\title{
An Inquiry into the integration of web-based information and dragon boat sport*
}

\author{
Gang JI, Peijun GAO
}

Jiujiang University, Jiujiang, Jiangxi, 332005

\begin{abstract}
The dragon boat sport, a folk sport item, is an emerging game with strong ethnic characteristics featuring body building, entertainment and competition. In teaching practice, folk sports courses embrace highly practical and participatory teaching activities. The athletic actions are easy to be demonstrated and imitated, which makes multimedia teaching activities feasible and efficient. The information construction of folk sports has ranked among the major trends and directions of China's higher education reform.
\end{abstract}

Keywords -Dragon boat sport; web-based information; integration

\section{探讨龙舟运动与网络推广的联姻 \\ 季刚 高培军 \\ 九江学院体育学院, 九江, 江西, 332005}

摘 要 龙舟运动是一项集健身、娱乐、竞技于一体的具有浓郁民族特色的新型体育运动。民俗体育是一项实践性和参与性极强 的教与学的双边活动, 其动作示范性和模仿性非常适合用一种多媒体内容的形式呈现。民俗体育信息化建设, 已成为我国高等教育 改革的趋势和主要方向之一。

关键词 龙舟运动, 网络信息化, 联姻

1. 前言

龙舟作为我国的优秀文化瑰宝，如何传承、诠释龙舟 文化，展现当代大学生团结拼搏、积极进取的时代精神, 是全国各高校刻不容缓的责任之一。民俗体育信息化建设， 已成为我国教育改革的趋势和主要方向之一。得益于互联 网技术的发展, 网络平台的出现, 大大利于龙舟文化的发 展、传播和资源共享。

\section{2. 传统龙舟的现代化}

龙舟作为中国民族传统体育进入现代社会, 必然会融 入现代体育文化氛围, 使传统民族体育传统的健身娱乐和 文化活动, 转化为一种独特的文化形式的运动和健身, 朝科 学、标准化, 转向技术、制度化、现代化、国际化的方向
发展。在社会主义发展市场经济的快速发展伴随下，我们的 生活节奏不断加快, 已然不允许散漫的龙舟运动在民间被 广泛开发。而龙舟运动的现代化、规范化和国际化是发展 大趋势。在国家教育部的推动下, 龙舟在国内外的高校内 发展迅速, 规模日趋壮大, 普及面广。中国大学生体育协 会在 2004 年创建了中国大学生体育协会和划龙船分公司 (以下只称呼为中国大学生龙舟协会或简称大学生龙协), 有利于高等学校的大学生利用业余时间开展龙舟运动, 强 身健体，又可以传承、振兴民族文化; 也利于提高高等院 校的龙舟运动水平。

*致谢：2014年江西省高校教改项目（JXJG-14-17-4）的阶段成果之一。

作者简介: 季刚 (1978-) 男, 江西永修人, 硕士, 九江学院讲师。主要从事体育教学及体育人文研究。 


\section{3. 高校龙舟运动发展的现状及特点}

\section{1 龙舟运动在高校开展的历史和现状}

高校龙舟运动在 “南舟北移” 和 “走出国门” 的政策 春风下, 传统的龙舟竞渡风俗得以在南部地区快速发展, 扩 展到香港、澳门、台湾等地, 向北扩展到天津、北京、辽 宁等经济发达的地区, 促进当地经济和文化的繁荣, 传承 优秀民俗文化。在天津龙舟协会成立于 1988 年, 并在天津 第一次举行龙舟邀请赛。此次比赛是以娱乐为主, 参与队 伍多, 天津师范大学、天津医科大学等多支高校代表队参 与竞争, 极大提高了高校学术参与龙舟的积极性和热情。

2004 年, 中国大学生龙舟协会成立于天津科技大学, 第一次加入会员有 37 所大学, 包括香港科技大学、澳门理 工学院。这标志着中国大学生龙舟运动都有自己的管理机 构和组织的竞争。2006 年 7 月, 中国高校大学生龙舟组织 首次参加在沈阳举行龙舟协会、辽宁省第 14 届 “屈原杯” 全国龙舟比赛。2006 年 10 月, 在天津顺利举行国际大学生 龙舟邀请赛和中国第一个大学生龙舟比赛。自此, 中国高 校龙舟运动的发展轨道日趋健康和规范。

随着中国龙舟运动的快速发展, 高校龙舟运动如今也 逐渐的趋于南北平衡, 不仅是南部的大学在龙舟运动方面 有着很大提升, 北边的大学也在快速上升, 包括北方的东北 电力大学、山东淮海理工学院, 它们都展示了他们强大的 竞技水平。在江西九江、广西已经成功举办了中国大学生 龙舟竞赛七站比赛的最前两站。在中国大学生龙舟协会的 推动下, 无论是龙舟竞赛的技术和战术都有着快速进展。现 在大学生龙舟协会成员单位, 作为大学生龙舟协会团队, 它 的影响力也逐渐扩大。到目前为止, 已经成功举办了六次中 国天津 “塘沽杯” 国际大学生龙舟邀请赛和三届中国大学 生龙舟比赛。目前, 大学生龙舟运动是向标准化、科学化、 制度化和国际化的方向发展。

\section{2 龙舟运动的特点}

“龙舟运动” 是多个运动员集体凭靠单叶片式划桨来 前进的一种运动方式, 使用肌肉力量将船向后划水, 水就会 把船推动向前移动。中国龙舟协会领先的配备标准龙头、 龙尾、鼓 (鼓手)、舵 (舵手), 这些都是为了保持中国民 间传统。在传统的龙舟比赛里, 可以考虑设置锣 (锣手)。根 据不同地区民俗的特点, 在设计上有风舟、象牙舟、龟舟、 虎头舟、牛头舟、天鹅舟、蛇舟等形状和名称, 同时也可 以保留原来的规范, 但只要是类似于划船运动都可以称为
龙舟运动。基于中国传统, 正规龙舟比赛舟船头都设龙头。

\section{4. 高校龙舟运动的积极意义}

4. 1 高校龙舟运动有利于培养和提高学生身心素质全 面发展。

4. 2 高校龙舟运动丰富了大学体育教育、教学内容和 校园体育文化的内涵, 促进校园文化的发展。

4. 3 由于开发利用区域环境优势, 高校龙舟运动促进 当地的体育、文化、经济、教育的全面协调发展。

4. 4 传统的龙舟运动, 可以传承传统民俗文化, 培育 爱国主义、凝聚力, 培养广大学生的团结合作的拼搏精神, 培养大学生的集体主义、合作互助的理念, 也巩固和弘扬 中国传统文化。

\section{5. 龙舟运动联姻网络的价值}

5. 1 龙舟文化的网络信息化的必要性

消失的不仅是一种文化遗产，民间文化枯竭也是非常 严重的。上海纪念 “非遗法” 颁布一周年学术研讨会披露, 上海约半数非遗项目处在濒危或有濒危可能的状态, 不少 非遗项目都已到了人老艺衰甚至人亡艺绝、后继无人的地 步。冯瀷才著名作家、艺术家, 民间艺术专家指出, 中国越 来越充满了遗产保护系统, 但没有减缓濒危和灭绝的速度。 无形的死亡的原因包括城市化、非基因研究者老化等各种 原因。

据悉, 2005 年 12 月, 国务院将每年六月的第二个星期 六为中国文化遗产日。自 2006 年以来, 国务院公布的第一 批国家级非物质文化遗产名录。有超过 1200 中无形的, 但 更多的保护无形价值未被包括在内。政府保护的同时，市场 也在发挥经济杜杆作用, 特别是互联网的出现, 促使许多卖 不好, 不能生产的体育项目, 可以通过互联网渗透到人们的 生活和经济链, 重新焕发了新的活力。在南部地区, 一个年 轻人做龙舟跟随老师学习, 并通过百度推广打破了龙舟的 消息, 实现文化价值和商业价值。在湖北, 林邱明通过百度 推广销售米雕刻的民俗文化的国家, 年销售额达到数百万。 今年 5 月, 百度联盟国内创建一个八个著名博物馆数字博 物馆, 让人们可以通过网络文化精品, 更方便平等对历史和 文化的理解。中国艺术学院音乐学院田指出, 经济发展的速 度太令人惊讶了, 我们的传统文化消失的速度惊人。古老传 统民间, 包括我们在面对现代化, 是一种弱势文化, 你不保 护它, 它将会消失。 


\section{2 龙舟网络推广的途径和方式}

借助网络推广, 可以大大发展龙舟运动, 传承龙舟文 化, 保护和开发出优秀的传统项目, 从而盘活龙舟市场, 盘活龙舟文化、更能延续中华有力的文化和民俗。许名南 是泪罗市九子龙屈原龙舟厂的负责人。他告诉《中国经营 报》记者: “没有足够大的市场力量, 方圆几十公里的市场 不足以支撑我们这些手艺。” 许名南的企业是用传统的手艺 打造木质龙舟, 与国内其他制造轮船来做钢龙舟有所不同。 他说, 如果不是网络推广帮助打开市场, 厂子可能早已关 门, 学了手艺的师兄弟们还会在外打工。“我们的顾客多在 民间, 民间的需求量很庞大。比如有赛龙舟的广东、福建、 湖南和江西等地, 也有一些度假村和公园购买, 把龙舟做 成旅游项目。如果靠传统的拉一条龙舟的展示推销, 根本 做不了外省的生意。” 许名南说, 用了网络推广这些有龙舟 需求的全国客户都会主动的联系我们, 现在北至黑龙江、 南至云南广东都有客户。虽然他只是卖龙舟的, 但是从他 的例子不难看出网络推广的重要性。

通过网络推广, 不仅可以保持龙舟运动资源, 还可以 扩大龙舟运动接受群众基础, 更能带来社会、经济和文化 多方面的价值。

5. 2 . 1 通过网络新闻媒体积极宣传关于高校龙舟赛 事的举办情况, 博得大众的关注, 取得公众对龙舟的支持 和理解。

5. 2.2 发起网络热点话题, 让大家都可以切身的去 参与其中。
5. 2.3 借助微博互动的形式, 进行网络龙舟赛的直 播，同时可以搭建一个高校专属的龙舟直播平台，让广大 的大学生们都可以去积极关注。

\section{6. 结束语}

龙舟运动是一项集健身、娱乐、竞技于一体的具有浓 郁民族特色的新型体育运动。他所有的独特的运动功能, 不仅可以强身健体, 同时也是一项非常好的培训参与者团 结合作能力和集体荣誉感的运动, 并且有很强的民族性和 群众性。我们要利用现有的信息化技术、网络平台来推广 龙舟运动, 发展龙舟运动, 传承龙舟文化, 以使优秀的民 俗体育-一龙舟运动永葆青春。

\section{参考文献(References)}

[1] The Current State and Characteristics of Dragon Boat Sport in Universities

[2] The Characteristics of Dragon Boat Sport Major and Its Regulations of Defeat

[3] The History and Culture of Dragon Boat Sport and Its Current Development

[4] Shaw Zhiling. Construction of University Dragon Boat Sport Curriculum System in China [D]. research of Wuhan Sports Institute 2009

[5] An Analysis on the Appliance of the Scientific Development Concept in Directing the Development of Dragon Boat Sports in Universities 